\title{
Reckoning HIV/AIDS care: A longitudinal study of community home- based caregivers and clients in Swaziland
}

\author{
Robin Root, $\mathrm{MPH}, \mathrm{PhD}^{1}$ \\ Arnau Van Wyngaard, $\mathrm{PhD}^{2} 3$ \\ Alan Whiteside, D Econ ${ }^{4}$
}

\begin{abstract}
The article is a descriptive case study of a community home-based care (CHBC) organization in Swaziland that depicts the convergence of CHBC expansion with substantially improved health outcomes. Comprised of 993 care supporters who tend to 3839 clients in 37 communities across southern Swaziland, Shiselweni Home-based Care (SHBC) is illustrative of many resourcelimited communities throughout Africa that have mobilized, at varying degrees of formality, to address the individual and household suffering associated with HIV/AIDS. To better understand the potential significance of global and national health policy/programming reliance on community health workers (taskshifting), we analyzed longitudinal data on both care supporter and client cohorts from 2008 to 2013. Most CHBC studies report data from only one cohort. Foremost, our analysis demonstrated a dramatic decline (71.4\%) among SHBC clients in overall mortality from $32.2 \%$ to $9.2 \%$ between 2008 and 2013 . Although the study was not designed to establish statistical significance or causality between SHBC expansion and health impact, our findings detail a compelling convergence between CHBC, improved HIV health practices, and declines in client mortality. Our analysis indicated (1) the potential contributions of community health workers to individual and community wellbeing, (2) the challenges of task shifting agendas, above all comprehensive support of community health workers/care supporters, and (3) the importance of data collection to monitor and strengthen the critical health services assigned to CHBC. Detailed study of CHBC operations and practices is helpful also for advancing government and donor HIV/AIDS strategies, especially with respect to health services decentralization, in Swaziland and similarly profiled settings.
\end{abstract}

Key words: Community home-based care, care supporter/caregiver, Africa, HIV testing, ART/ARV, adherence, gender, HIV/AIDS policy, religion, task shifting

\footnotetext{
${ }^{1}$ Department of Sociology \& Anthropology, Baruch College, City University of New York, New York, USA

${ }^{2}$ Department of Science of Religion and Missiology, University of Pretoria, South Africa

${ }^{3}$ Shiselweni Home-Based Care, Swaziland

${ }^{4} \mathrm{CIGI}$ Chair in Global Health Policy, Balsillie School of International Affairs and Wilfrid Laurier University, Waterloo, Canada
} 


\section{Introduction}

Operating in remote rural areas of Shiselweni, the southernmost and leastresourced region of Swaziland, Shiselweni Home-Based Care (SHBC) is similar to community health initiatives throughout Africa: it is volunteer-based, grassroots in origin, faith-based, and staffed primarily by women. Unlike most community home-based care (CHBC) organizations, however, SHBC initiated and has maintained data on its operations, caregivers, and clients almost from its inception in 2006. In this article, we present a descriptive analysis of this longitudinal dataset that is instructive on multiple fronts. In particular, national governments, including the Swazi government (Sibbald 2013), and global health agencies have increasingly emphasized decentralization of health services and 'treatment as prevention' (TasP) for HIV/AIDS (Stop AIDS Now 2014) as priority initiatives. Toward this end, the WHO recently introduced guidance documents advising TasP as part of a continuum of care that will significantly impact global and country HIV/AIDS financing, policies, and programming (WHO 2013b).

However, little is known about the most effective configurations of care continuums (Uys 2003a; Campbell, Nair, Sbongile, \& Zweni 2008), including community-based roles, in highly variable settings marked by different political-economies, disease burdens, health services infrastructure, and cultural milieus. Scholars have called for substantially more research to better understand the contextual factors that may support or hinder diversely constituted home-based care initiatives (Uys 2003a; Wringe, Cataldo, Stevenson \& Fakoya 2010; Campbell, Nair, Sbongile, \& Zweni 2008; Apondi, Bunnell, Awor, Wamai, Bikaako-Kajura, Solberg et al. 2007). To contribute to this agenda, our descriptive case study of SHBC's uncommonly large longitudinal dataset generated insights on the operations and potential significance of HIV-related home-based care services, as reflected in HIV testing and ARV uptake as well as reduced mortality. Our analysis of these data strongly suggested (1) the facilitative potential of $\mathrm{CHBC}$ to improve individual and community health, (2) the challenges of task shifting agendas, above all training, comprehensive support, and retention of care supporters, and (3) the importance of longitudinal 
data collection and periodic analysis by $\mathrm{CHBC}$ to monitor and strengthen critical health services assigned to these diversely configured entities.

\section{Background}

\section{Swaziland: HIV/AIDS government policy and epidemiology}

Swaziland, a small landlocked nation in southern Africa, has long been marked as the nation with the world's highest HIV prevalence rates. Though HIV incidence (2.6\%) has stabilized in recent years, the country's hyperendemic state is indicated by an HIV prevalence of $32 \%$ among adults age 1849 years. The gendered vulnerabilities are seen in highly disparate rates between adult men (24\%) and women (39\%), where women's rates peak both earlier than men's (age 30-34 vs. age 35-39) and higher (54\% vs. 47\%) (Bicego, Nkambule, Peterson, Reed, Donnell \& Ginindza et al. 2013). Signaling recent policy successes in ART rollout, however, approximately $83 \%$ of PLWHA in need of treatment are receiving it. Likewise, access to PMTCT services has improved significantly in recent years; unfortunately, HIV prevalence among women attending antenatal clinics has remained intransigently high (41\%) (Ministry of Health 2013:9).

Governmental responses to the HIV/AIDS epidemic have been mixed. In 1993, Swaziland was the first country to identify AIDS as a significant issue in its national development plan. In the 1990s, standard short and mediumterm plans were put in place with support from the WHO's Global Programme on AIDS and the Swaziland National AIDS Programme. In 1999, the country's absolute monarch, King Mswati III, proactively declared the epidemic a national disaster. Two years later, the government recognized the need for exceptional and multisectoral action by establishing the National Emergency Response Council on HIV and AIDS (NERCHA). Confusing HIV/AIDS messages on the part of the government and some donor-backed initiatives subsequently may have compromised the potential effectiveness of selected HIV/AIDS initiatives (AVERT n.d.; Smith \& GlobalPost 2012). 
The government's National Strategic Framework (NSF) 2009-2014 (Government of Swaziland 2009) outlined a comprehensive critique of deficiencies in government management, monitoring, coordinating, and resourcing of community-based care services and articulated a concern over the high care burdens shouldered by women and girls. Importantly, it also identified inadequate documentation of care services as an obstacle to NSF implementation, a deficiency that this article, in describing and analyzing CHBC data, aims to address.

Though the government has increased spending on health and is above the Abuja target of $15 \%$ of the government budget, it still faces dire human resource shortages (Africa Health Workforce Observatory [AHWO] 2009). In 2009 (the last year for which data are available), the country had only 0.14 general physicians per 1000 people (AHWO 2009:24). Formal health facilities are owned primarily by governmental (44.8\%) and private $(22.4 \%)$ entities, and the remaining third is split among faith-based institutions (14.8\%), industrial facilities (12.6\%), and NGOs (5.4\%) (UNICEF 2013). Faith-based and mission health services are integral to the national health systems infrastructure in Swaziland (AWHO 2009), which further contextualizes the tangible operations and HBC practices of a faith-based CHBC such as SHBC. Approximately $80 \%$ of Swazis live within $8 \mathrm{~km}$ of a public clinic (Zwane 2005); however, public transportation is expensive and once a person is unwell, travelling even short distances can be physically impossible, which further imperils individuals' health. These oft-insuperable obstacles to clinic-based health services have rendered well-designed and resourced CHBC essential for the success of HIV/AIDS and TB initiatives. Promisingly, home-based HIV/AIDS and TB services have been expanding in Swaziland with demonstrated effectiveness (University Research Co. 2010).

\section{Shiselweni Home-Based Care: Background, expansion, and budget}

Of the country's four regions, Shiselweni is the least resourced for addressing its population's health needs. In 2006-2007, only $11 \%$ of health facilities in Shiselweni were staffed with a health worker trained comprehensively in 
HIV and AIDS, and no health facility had Internet access (Kingdom of Swaziland 2008). This is the setting in which SHBC has provided home-based care outreach in rural areas since 2006.

SHBC began as a single congregational initiative for parishioners to provide assistance to the many individuals who were unwell in their communities. Beginning with 32 volunteers, it expanded to 993 care supporters tending to nearly 4000 clients in 37 communities by the end of 2013. As part of the formalization of SHBC (Figure 1), the founder ${ }^{5}$, a South African missionary with the Dutch Reformed Church in South Africa (Van Wyngaard 2006a, 2006b), became its CEO. The organization's composition and operations, however, is indigenous to Swaziland, with a longstanding member of the community serving as its chief operating officer (COO).

Figure 1: SHBC growth and expansion

SHBC Timeline

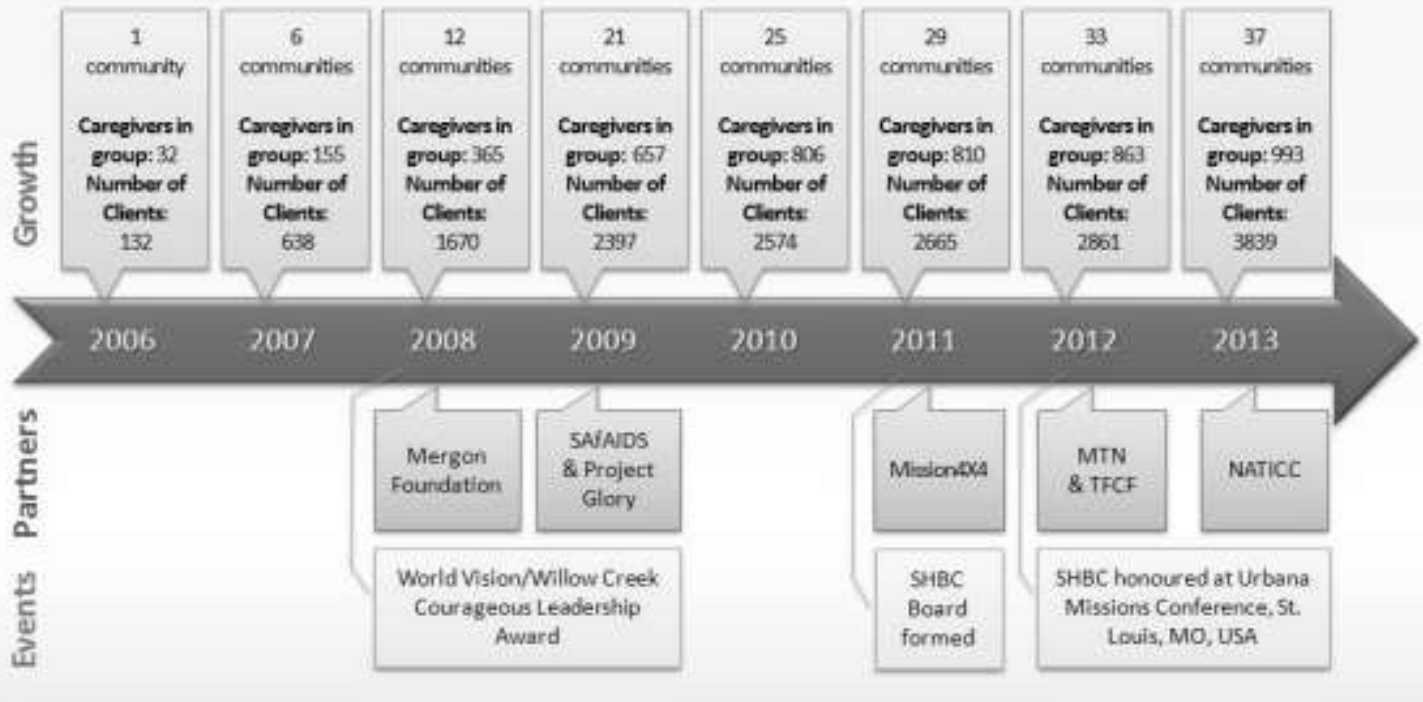

Care supporters are trained in HIV prevention, stigma reduction, brokering disclosure, and ART and TB treatment support. In addition, like many faithbased community initiatives in Africa, SHBC is Christian in its care ethos and includes prayer and Bible reading as a home-based care practice, depending on clients' comfort level with such activities.

${ }^{5}$ One of this article's authors. 
For the first two years of its existence, SHBC income consisted mostly of small donations from individuals who knew the pastor personally and were sympathetic towards the vision of SHBC. In 2008, SHBC was nominated for the Courageous Leadership Award, co-sponsored by World Vision and Willow Creek Association. The award was a turning point on two counts. First, externally, the award's international recognition strengthened SHBC candidacy for partnerships and worthwhileness as a funding recipient. This led to SHBC's first partnership, with Mergon Foundation, which committed to a guaranteed monthly contribution used mainly for training new groups in neighboring communities. Internally, the cash award allowed SHBC to expand its capacity to care for vulnerable children in its anchoring community by financing the construction of a kitchen and dining area. Previously, meals had been prepared in a large cast-iron pot over an outdoor wood fire.

Like many community-based health initiatives, SHBC has operated on a small budget relative to the tasks undertaken. The latest figures indicate that SHBC total income in 2013 was R1 355 000. Total expenses for the same period were R1 264000 for 3839 clients. A majority of these funds were dedicated to client-related expenditures, which included provisioning care supporters with food to support themselves and, at their discretion, their clients, especially those on ART, and basic medications. The bulk of the remaining funds finance the training of existing and new care supporters. Overheads have been restricted to the absolute minimum ( $1 \%$ of expenses).

In response to requests that SHBC calculate the value of its services, a notional figure of R500 per month per care supporter is used, the amount paid by the Swaziland government to its rural health motivators (who do not routinely do house visits). By this calculation, the value for work rendered by SHBC care supporters in 2013 was estimated at R5 958 000. All those involved with SHBC, including the CEO (as part of his missionary work) and board members, do so as volunteers. 


\section{Study methods}

A descriptive case study of SHBC's longitudinal data entailed analysis of the following trends: (1) community uptake and expansion; (2) care supporter enrollment, socio-demographics, number of home visits and client load; (3) client socio-demographics, clinic referrals, ARV/TB treatment status; (4) the convergence of these trends with reduced client mortality. Home-based care practices intended to engender HIV health practices among clients are also described, and recent data on care supporter attribution are also presented.

Data collection commenced in the third year of SHBC operations (2008) and occurred in the following manner: care supporters travel in pairs, in part to support but also to monitor peers' care work and data collection. Each care supporter is required to keep record of every client visit on a printed report form. Client anonymity is protected through use of clients' initials only. At the end of each month, every community coordinator compiles a report, which is submitted to the $\mathrm{COO}$ for further review and compilation. This report in turn is sent to the CEO for tracking important metrics.

The rationale for a descriptive analysis of SHBC data is based on two prior HIV-related studies in Swaziland. A 2002 published report examined death notices in one of Swaziland's main local newspapers as a proxy to track trends in mortality (Whiteside, Desmond, King, Tomlinson \& Sithungo 2002). Findings from that study served as an important advocacy tool showing a reality that was not otherwise being recognized. The second study utilized data from the main undertaker in Swaziland to track funeral practices and costs (Desmond, King, Tomlinson, Sithungo, Veenstra \& Whiteside 2004). Analysis and interpretation of SHBC data presented here was further informed by published research on SHBC care supporters' experiences (Root \& Van Wyngaard 2009) and SHBC clients' perceptions of care supporters' impact on ART adherence (Root \& Whiteside 2013).

\section{Study limitations}

First, in the absence of an experimental or quasi-experimental design, 
ascertainment of statistical significance and causality between SHBC services and mortality impact was not possible. Second, it is difficult to assess the veracity of every datum collected by care supporters over the six-year period. Quality control measures (paired care supporters observe one another and the COO makes "drop in" visits to coordinators to inspect intra-monthly data collection) suggest the data are sufficiently valid for interpreting trends in homebased care services and aspects of clients' health. Minor deviations from virtually any of the metrics would detract little from the major finding that substantial morbidity and mortality appear to have been allayed by the organization and that its operations are expanding rapidly. Last, although descriptive statistics are limited in their generalizability, the longitudinal data analyzed here are sizable for a CHBC; the numbers of care supporters and clients increased substantially over the study period to 993 and nearly 4000 clients, respectively, and key demographic and health practices data were frequently collected in tandem with government ART rollout.

\section{Results}

This section reports descriptive statistics of a longitudinal dataset pertaining to care supporter and client cohorts. The data are uncommon in their detailing the 'life course' of a rural organization from an informal to a formal entity and its continuing challenges, which are characteristic of similar initiatives throughout Africa that do not have such data tracking capabilities.

\section{Growing the base: care supporters and expansion}

Like most community-based care initiatives and church congregations in Africa, SHBC's volunteer base began and has remained overwhelmingly female (Table 1). By 2013, one-third (35.3\%) were between the ages of 46-55 years and more than a quarter (27.5\%) between the ages of 36-45. Almost equal numbers were between the ages of 26-35 (15.7\%) and 56-65 (14.9\%). The remainder was older than age 65 (5.1\%), and between ages 20-25 (1.5\%). 
Table 1: Number of care supporters by gender and of participating communities

\begin{tabular}{|c|c|c|c|c|}
\hline Year & Female & Male & Total & $\begin{array}{c}\text { Number of commu- } \\
\text { nities }\end{array}$ \\
\hline $\mathbf{2 0 0 6}$ & $24(75 \%)$ & $8(25 \%)$ & 32 & 1 \\
\hline $\mathbf{2 0 0 7}$ & $142(91.6 \%)$ & $13(8.4 \%)$ & 155 & 6 \\
\hline $\mathbf{2 0 0 8}$ & $349(95.6 \%)$ & $16(4.4 \%)$ & 365 & 12 \\
\hline $\mathbf{2 0 0 9}$ & $563(95.3 \%)$ & $28(4.7 \%)$ & 591 & 21 \\
\hline $\mathbf{2 0 1 0}$ & $723(96.3 \%)$ & $28(3.7 \%)$ & 751 & 25 \\
\hline $\mathbf{2 0 1 1}$ & $779(96.2 \%)$ & $31(3.8 \%)$ & 810 & 29 \\
\hline $\mathbf{2 0 1 2}$ & $827(95.8 \%)$ & $36(4.2 \%)$ & 863 & 33 \\
\hline $\mathbf{2 0 1 3}$ & $949(95.6 \%)$ & $44(4.4 \%)$ & 993 & 37 \\
\hline
\end{tabular}

Between 2008, when SHBC began data collection, and December 2013 , there was a $172 \%$ increase in the number of volunteer care supporters from 365 to 993 individuals. Four years into its operations, 9 new communities were added, which grew its volunteer base $80 \%$, an expansion that was determined shortly thereafter to have been too fast. Extending personal attention to the care coordinators in order that the CEO could address coordinators' needs was deemed essential in order that coordinators themselves could tend to the needs of their care supporters in ways that, in turn, modeled how care supporters tend to clients. A limit thus was put in place at four new communities a year to effectively balance communities' desires to be trained and SHBC emphasis on monitoring care training and services quality.

In addition to word-of-mouth communication, whereby groups in adjacent communities request an SHBC training, four sociocultural processes help to explain SHBC's rapid expansion. First, the philosophy of Ubuntu is indigenous to southern Africa. At its core, Ubuntu serves ontologically and epistemologically to structure individual consciousness in communitarian terms (Forster 2006).

Second, the SHBC vision is articulated in terms of "Being the hands 
and feet of Christ in this community," emblazoned in siSwati, the country's predominant language, on care supporters' mustard-colored T-shirts. This discursively Christian messaging provides an ideological and organizational foundation for collective affiliation and social action that is recognizably religious (Van Wyngaard 2013). Both philosophies, Ubuntu and Christian, thus constitute, and are constituted by, collective and individual actions to redress social suffering.

Third, in addition to these belief systems, high morbidity and mortality in the communities where SHBC originated meant that many people were already looking after family members and thus eager to improve their ability to assuage suffering. By meeting in an ongoing manner in people's homes (where client needs and household composition are always in flux), SHBC support made family members' acquisition of vital care skills economically and logistically feasible.

Finally, community leaders, including local chiefs, who had been without means of strengthening household care capacities amidst worsening sickness and poverty observed the positive impact of care supporters and requested SHBC come train its own volunteer corps. Consultative communication with chiefs has been integral to SHBC expansion.

Care supporters are provisioned with food parcels, for themselves and clients, as well as medical backpacks to assist them in scaling up of their services. The organization's T-shirt, which is given upon completion of training, is intended to enable care supporters to approach a house with a certain authority and to make them more acceptable to the community. Inclusion of a Bible in the medical backpacks enacts the fusion of biomedical and socio-religious care. These fused care practices were mirrored in a study of SHBC clients' perceptions of their care supporters, which showed that the vast majority viewed them as both "health" and "religious" persons (Root \& Whiteside 2013).

From 2008 to 2013, the total number of home-based visits (Table 2), whereby a paired team of care supporters visits client(s) at a homestead, increased $160 \%$. Over the same period, the ratio of clients per care supporter 
decreased from 4.6 to 3.9 , despite a particularly marked increase $(34.2 \%)$ in home visits between 2012 and 2013. Nonetheless, an expanding volunteer base may help to explain the slightly lesser client load. Also, as some clients regained their health, it may have become unnecessary for care supporters to continue regular visits.

Table 2: Total number of SHBC homestead visits and clients per care supporter

\begin{tabular}{|c|c|c|}
\hline Year & Care supporter client visits & Clients per care supporter \\
\hline $\mathbf{2 0 0 8}$ & 39743 & 4.6 \\
\hline $\mathbf{2 0 0 9}$ & 50240 & 4.1 \\
\hline $\mathbf{2 0 1 0}$ & 66948 & 3.4 \\
\hline $\mathbf{2 0 1 1}$ & 70795 & 3.3 \\
\hline $\mathbf{2 0 1 2}$ & 69864 & 3.3 \\
\hline $\mathbf{2 0 1 3}$ & 103381 & 3.9 \\
\hline
\end{tabular}

Importantly, once a month all coordinators meet to debrief and identify further training needs. These gatherings have proven essential for sustaining and invigorating care coordinators, as they oversee a total of almost 1000 care supporters, and are believed to have been crucial to SHBC success. (For a study of SHBC care supporter experiences, see Root \& Van Wyngaard 2009.)

In 2012, it became apparent that the energy and enthusiasm of care supporters to undertake home visitation was flagging. In 2013, the founding pastor and $\mathrm{COO}$ began using the occasion of monthly care coordinator meetings to share with care coordinators the impact of their work, including the reduced mortality rates. Care coordinators, in turn, shared knowledge of this impact with care supporters in their respective communities, which may also have invigorated in home visitation to explain the turn upwards in 2013.

In an attempt to better understand why care supporters may cease their SHBC involvement, in 2013 coordinators who had observed care supporters to 
cease volunteering were encouraged to meet with these individuals to discuss the reasons why. Of the 122 individuals who could be tracked who had left the organization since 2006 , more than a third $(35.2 \%)$ had died; $12.3 \%$ had become too sick to continue volunteering; $11.5 \%$ reported that they had suffered from burnout; $21.3 \%$ had found other work or lost interest (3.3\%); $10.7 \%$ had expected to be paid; and $5.7 \%$ had relocated to other areas.

\section{Widening the net: SHBC clients}

Since its inception, women have comprised approximately two-thirds and men one-third of SHBC clients (Table 3).

Table 3: SHBC client base, by gender

\begin{tabular}{|c|c|c|c|}
\hline Year & Female & Male & Total \\
\hline $\mathbf{2 0 0 8}$ & $1092(65.4 \%)$ & $578(34.6 \%)$ & 1670 \\
\hline $\mathbf{2 0 0 9}$ & $1527(63.7 \%)$ & $870(36.3 \%)$ & 2397 \\
\hline $\mathbf{2 0 1 0}$ & $1606(62.4 \%)$ & $968(37.6 \%)$ & 2574 \\
\hline $\mathbf{2 0 1 1}$ & $1640(61.5 \%)$ & $1025(38.5 \%)$ & 2665 \\
\hline $\mathbf{2 0 1 2}$ & $1739(60.8 \%)$ & $1122(39.2 \%)$ & 2861 \\
\hline $\mathbf{2 0 1 3}$ & $2372(61.8 \%)$ & $1467(38.2 \%)$ & 3839 \\
\hline
\end{tabular}

The largest cohort has continuously been over the age of 40 years, followed in most years by clients aged 35-39 years. Nationally, children aged 014 years comprise $19 \%$ of all new HIV infections, and HIV/AIDS is the leading cause of death among children under age five (United Nations 2012). Among SHBC clients, infants and children are a smaller but nonetheless sizeable cohort (10\%) (Table 4). 
Table 4: SHBC client base, by age cohort and percentage of total

\begin{tabular}{|c|c|c|c|c|c|c|c|}
\hline Year & $0-14$ & $15-19$ & $20-24$ & $30-34$ & $25-29$ & $35-39$ & $40+$ \\
\hline 2008 & $\begin{array}{c}156 \\
(9.3 \%)\end{array}$ & $\begin{array}{c}165 \\
(9.9 \%)\end{array}$ & $\begin{array}{c}60 \\
(3.6 \%)\end{array}$ & $\begin{array}{c}121 \\
(7.2 \%)\end{array}$ & $\begin{array}{c}146 \\
(8.7 \%)\end{array}$ & $\begin{array}{c}162 \\
(9.7 \%)\end{array}$ & $\begin{array}{c}860 \\
(51.5 \%)\end{array}$ \\
\hline 2009 & $\begin{array}{c}221 \\
(9.2 \%)\end{array}$ & 94 (3.9\%) & $\begin{array}{c}147 \\
(6.1 \%)\end{array}$ & $\begin{array}{c}165 \\
(6.9 \%)\end{array}$ & $\begin{array}{c}209 \\
(8.7 \%)\end{array}$ & $\begin{array}{c}257 \\
(10.7 \%)\end{array}$ & $\begin{array}{c}1304 \\
(54.4 \%)\end{array}$ \\
\hline 2010 & $\begin{array}{c}290 \\
(11.3 \%)\end{array}$ & $\begin{array}{c}104 \\
(4.0 \%)\end{array}$ & $\begin{array}{c}110 \\
(4.3 \%)\end{array}$ & $\begin{array}{c}165 \\
(6.4 \%)\end{array}$ & $\begin{array}{c}213 \\
(8.3 \%)\end{array}$ & $\begin{array}{c}327 \\
(12.7 \%)\end{array}$ & $\begin{array}{c}1365 \\
(53.0 \%)\end{array}$ \\
\hline 2011 & $\begin{array}{c}246 \\
(9.2 \%)\end{array}$ & $\begin{array}{c}104 \\
(3.9 \%)\end{array}$ & $\begin{array}{c}106 \\
(4.0 \%)\end{array}$ & $\begin{array}{c}177 \\
(6.6 \%)\end{array}$ & $\begin{array}{c}236 \\
(8.9 \%)\end{array}$ & $\begin{array}{c}276 \\
(10.4 \%)\end{array}$ & $\begin{array}{c}1520 \\
(57.0 \%)\end{array}$ \\
\hline 2012 & $\begin{array}{c}276 \\
(9.6 \%)\end{array}$ & $\begin{array}{c}112 \\
(3.9 \%)\end{array}$ & 96 (3.4\%) & $\begin{array}{c}146 \\
(5.1 \%)\end{array}$ & $\begin{array}{c}249 \\
(8.7 \%)\end{array}$ & $\begin{array}{c}342 \\
(12.0 \%)\end{array}$ & $\begin{array}{c}1640 \\
(57.3 \%)\end{array}$ \\
\hline 2013 & $\begin{array}{c}367 \\
(9.6 \%)\end{array}$ & $\begin{array}{c}143 \\
(3.7 \%)\end{array}$ & $\begin{array}{c}127 \\
(3.3 \%)\end{array}$ & $\begin{array}{c}226 \\
(5.9 \%)\end{array}$ & $\begin{array}{c}322 \\
(8.4 \%)\end{array}$ & $\begin{array}{c}416 \\
(10.8 \%)\end{array}$ & $\begin{array}{c}2238 \\
(58.3 \%)\end{array}$ \\
\hline
\end{tabular}

When care supporters suspect that a child might be HIV-positive, they approach the parent(s) to discuss concerns and options for testing. If a child is on ARVs, which are taken in the form of a syrup twice a day, the care supporter works to ensure that the parent understands that the child needs to take the syrup at a specific time each day, usually at 7 am (before school) and then again at $7 \mathrm{pm}$. The care supporter will regularly visit the parent during the early stages to ensure adherence has been achieved.

Between 2008 and 2013, care supporters reported a total of $19741 \mathrm{HIV}$ testing and counseling (HTC) referrals (Table 5).

Table 5: SHBC clinic referrals

\begin{tabular}{|c|c|c|c|c|c|}
\hline Year & HTC & ARV & TB & STI & TOTAL \\
\hline $\mathbf{2 0 0 8}$ & 3320 & 1792 & 2581 & 419 & 8112 \\
\hline $\mathbf{2 0 0 9}$ & 3389 & 1850 & 2506 & 592 & 8337 \\
\hline $\mathbf{2 0 1 0}$ & 3099 & 1856 & 2857 & 620 & 8432 \\
\hline $\mathbf{2 0 1 1}$ & 3084 & 2075 & 2345 & 796 & 8300 \\
\hline $\mathbf{2 0 1 2}$ & 3184 & 2287 & 2757 & 500 & 8728 \\
\hline $\mathbf{2 0 1 3}$ & 3665 & 2748 & 2662 & 645 & 9720 \\
\hline TOTAL & 19741 & 12608 & 15708 & 3572 & 51629 \\
\hline
\end{tabular}


In some years, the total number of HTC referrals was greater than the total client base for three reasons. Care supporters indicate on reporting forms those steps that clients have been advised to take. One of these is HIV testing. When clients are tested for HIV and the result is negative, care supporters advise that six months later they seek confirmatory testing; thus, a single individual may be referred for testing on two different occasions. Much of the time, however, the high number of referrals reflects the fact that a care supporter may have counseled a client to seek testing and indicated this on his or her form, yet upon return discovers that that person has not been tested and is advised once again to do so; this second referral is also reported. Finally, some individuals who are not (yet) clients may also be referred for testing, and this too is indicated on the form.

There were a total of 12608 ARV referrals ${ }^{6}$ over the six-year period (Table 5), a period that coincided with the government's national ARV rollout. The number of SHBC clients on ARVs increased dramatically from 2008 to 2009 (94.5\%), rising $26.7 \%$ the following year (Table 6). It is likely that some portion of these clients benefited by SHBC adherence support practices (Root \& Whiteside 2013).

Table 6: SHBC clients on HIVIAIDS and TB treatments, mortality rate

\begin{tabular}{|c|c|c|c|}
\hline Year & $\begin{array}{c}\text { ARV } \\
\text { (\% of SHBC client base) }\end{array}$ & $\begin{array}{c}\text { TB } \\
(\% \text { of SHBC client base) }\end{array}$ & Deaths/rate \\
\hline $\mathbf{2 0 0 8}$ & $364(21.8 \%)$ & $292(17.5 \%)$ & $538(32.2 \%)$ \\
\hline $\mathbf{2 0 0 9}$ & $708(29.5 \%)$ & $427(17.8 \%)$ & $506(21.1 \%)$ \\
\hline $\mathbf{2 0 1 0}$ & $897(34.8 \%)$ & $453(17.6 \%)$ & $483(18.8 \%)$ \\
\hline $\mathbf{2 0 1 1}$ & $1001(37.6 \%)$ & $358(13.4 \%)$ & $403(15.1 \%)$ \\
\hline $\mathbf{2 0 1 2}$ & $1106(38.7 \%)$ & $429(15.0 \%)$ & $331(11.6 \%)$ \\
\hline $\mathbf{2 0 1 3}$ & $1582(41.2 \%)$ & $381(9.9 \%)$ & $353(9.2 \%)$ \\
\hline
\end{tabular}

${ }^{6}$ Care supporters denoted when they have counseled clients to speak with clinic staff about beginning ARVs. However, it is possible that care supporters may have recorded a 'referral' when they counseled clients to seek ARV prescription refills. SHBC is working to determine if there is a discrepancy in this regard as part of its ongoing monitoring and evaluation of data reporting. 
From 2008 to 2013, clinic referrals for ARV (uptake/or management) increased 53.3\% (Table 5), and the number of clients reportedly on ART more than three-fold (335\%) (Table 6). This increase manifested in a percentage increase of SHBC clients on ARVs from $21.8 \%$ to $41.2 \%$. Over the six-year reporting period, client mortality rates declined from $32.2 \%$ to $9.2 \%$ (Table 6).

Because Swaziland's population also suffers from the world's highest TB rate, SHBC care practices address and monitor clients' TB referrals and medication adherence as well. Thus, TB testing referrals increased by $10.7 \%$ between 2008 and 2010 (Table 5). The following year, however, TB referrals declined $18 \%$ and client base on TB medications by $21 \%$. These rates turned upward in 2012 by $17.6 \%$ (referrals) and 19.8\% (on TB meds), respectively. One reason for the periodic declines in TB referrals and clients on TB treatment may have been attributable to changes in ARV protocols. The lower the CD4 count, the higher the probability of developing TB. In 2010, the WHO advised that the threshold for people to start with ART should be raised from a CD4 count of 200 to 350 . Swaziland was one of the first countries to implement the new threshold in 2011. Simultaneously, Swaziland also started to improve access to ART. Treating HIV-positive persons earlier may have enhanced individuals' immune systems and thereby decreased the number of TB infections.

Between 2008 and 2013, the proportion of SHBC clients, generally the most sick, receiving food assistance from their care supporters increased from $3.6 \%$ to $7 \%$. Given that a majority of care supporters as well as clients were and remain food poor, hunger remains a critical and enduring obstacle to improved health. World Vision, UNICEF, and a few other international organizations have periodically donated Power Meal, a form of pre-cooked maize meal very high in vitamins that has proven to be an excellent means of strengthening the extremely ill.

\section{Discussion}

This article examined longitudinal data on a rapidly expanding CHBC organization in a direly vulnerable region of Swaziland to describe trends in 
geographic expansion and community uptake, care supporter enrollment and client load, client sociodemographics and HIV/TB health status, and HIV testing and ARV practices. Though it was not possible to establish causality, these trends appear to track in meaningful ways with a dramatic decline in overall client mortality $(71.4 \%)$ from approximately one in three $(32.2 \%)$ clients to one in ten $(9.2 \%)$ in a six-year period. This reduction of $71.4 \%$ was approximately double the decline in national HIV/AIDS mortality rates (35.4\%) over roughly the same period (2007 and 2011) (WHO 9009; WHO 2013c). Thus, while the proportion of SHBC's reduced mortality attributable to prevention of HIVrelated deaths is unknowable from these data, national HIV/AIDS mortality rates strongly suggest the proportion of HIV-related deaths averted by SHBC care supporters likely has been substantial.

\section{Home-based care and AIDS 'talk'}

Since 2006, SHBC care supporters have brought about exceptional situations in which HIV prevention as well as ART and TB treatment support have been enacted on a regular and ongoing basis. In 2011, a national survey in Swaziland showed that $40 \%$ of PLWHA in Swaziland reportedly had not had a constructive conversation with a health care professional about AIDS treatment (SWANNEPHA 2011). The SHBC pushback against the silencing dynamic perpetuated and exacerbated by HIV stigma has provided strategic and continuous, real time counseling, where the $\mathrm{CHBC}$ relationship itself constituted the intervention. The 'AIDS talk' that transpired between SHBC care supporters and their clients thus was likely extremely consequential for reducing stigma and shame and encouraging HIV-related health practices.

The high number of home visitations (over 103000 in 2013) during which counseling, education, stigma reduction, and disclosure brokering happened with clients and, when possible, family members, thus appear to be key mechanisms by which critical HIV practices that lengthen life were enabled. The likelihood that these structured social interactions helped to achieve these results is supported by Campbell et al. who argue that multiplying the number of "community conversations" around HIV/AIDS has the potential to mobilize 
innovative community responses to the epidemic, in large part by creating safe spaces within which to speak about these issues (2013).

\section{Home-based care and gender-based initiatives}

As Campbell et al. have also noted, however, the potential impact of these social actions is direly constrained by famine, poverty, and poor governance (2013). Unable to intervene in the macro structural drivers that fuel the epidemic (Hickel 2012; Uys 2003b), SHBC has nonetheless undertaken to address some of these drivers. Its partnership with the regional Nhlangano AIDS Training Information and Counseling Centre (NATICC), for example, aims to address some aspects of gender-based violence (GBV) that differentially imperil women and children's economic and HIV-related vulnerabilities on the basis of, in many settings, their subordinate status. When clients report physical and/or sexual violence, or if such violence is evident to SHBC caregivers, caregivers are able to call a toll-free NATICC support line number on behalf of the client. NATICC has direct contact with the police who would then send members of the police force who specialize in addressing domestic violence.

In light of the complex, entrenched interpolation between socio-economic and socio-cultural dynamics that entrench GBV, the term has been extended from its original 1993 formulation by the United Nations (UNHCR) to include "any harm that is perpetrated against a person's will that is the result of power imbalances that exploit distinctions [based on gender]" and that "may be physical, sexual, psychological, economic, or socio-cultural' (Reach Out Refugee Protection Training Project 2005:5, emphasis added). To intervene in some of the micro structural processes that engender economic and socio-cultural violence in Swaziland, SHBC has included modules in care supporter training sessions to assist women in writing wills. In a society where customary laws privilege husbands' families in cases of property inheritance that risk further impoverishing a woman upon his death, equipping wives/women with the ability to exercise their small but expanding legal rights to property ownership could prove momentous. 
In addition, by brokering HIV disclosure between spouses that encourages HIV-healthy practices by both partners, SHBC has constructively intervened in a realm where many women in Swaziland are profoundly restricted in their ability to protect themselves and where outside agencies are not able to go: the homestead. Documenting and reflecting upon these initiatives is one means by which CHBCs may appropriately intervene in deeply entrenched structural vulnerabilities.

\section{Home-based care and preventing burnout}

Just as studies have shown "burnout" among formal health care workers and CHWs who provide HIV/AIDS services (Zachariah, Ford, Philips, Lynch, Mazzaquoi et al. 2009), SHBC data on care supporter deaths and sickness, as well as attrition, are critically important and strongly demonstrate that intervening to care for sick care supporters with directed health services is urgently needed. As well, prevention of burnout is essential to the wellbeing of individuals and sustainability of the organization. While some SHBC care supporters have left to join organizations that do provide material compensation, many SHBC care supporters and clients hew to a belief that volunteerism, as articulated in SHBC's Christian ethos, is more likely to ensure exceptional and qualitatively different care from, for example, other community health workers.

A philosophy and practice of volunteerism, however, has not prevented SHBC from addressing its care supporters' material, emotional, and burnout related challenges. To address disengagement and burnout, an initiative to train care coordinators to identify stress-related symptoms in their care supporters was introduced in 2012. Enhancing care supporters' own wellbeing through peer counseling and clinic support is intended also to help mitigate their own and family members' vulnerabilities, which could be especially beneficial for care supporters who are HIV positive. A second initiative has aimed to secure a reliable food supply for care supporters. In the absence of other income generating activities (or national strategies to support subsistence agriculture), external support for this program has been necessary. 


\section{Home-based care and occupational segregation}

A review of studies examining community health worker ( $\mathrm{CHW}$ ) impact on HIV care in SSA found that CHWs may well constitute a "part of the solution to the human resource crisis" in SSA, provided there is substantive economic and symbolic recognition, clear role definition, and much better integration and coordination with large health systems (Mwai, Mburu, Torpey, Frost, Forn, \& Seeley 2013:11). While task-shifting may help to resolve some human resource shortages (WHO 2008:preface), studies have also shown that it may exacerbate care burdens already shouldered by women and girls, especially when little is offered in the way of actionable strategies to alleviate these burdens (Akintola 2006; Opiyo, Yamano, \& Jayne 2008).

Some researchers have called for comprehensive interventions in local gender ideologies that would address the drivers of occupational segregation by gender with respect to care work (Newman, Fogarty, Makoae and Reavely, 2011). Such approaches may be incremental and likely entail interventions in extremely sensitive areas of cultural life. In contrast, Ogden, Esim, and Grown (2006) have recommended a policy/programmatic approach to valuation of care services as public goods that would warrant requisite frameworks for financing and support, an agenda that could elevate the status of care work even as it remains primarily the venue of women. For SHBC, engaging gendered divisions of care work and care burdens have entailed separate but related challenges. Men's participation in SHBC has remained very low and stable over time. For some women, SHBC work has enabled an expansion of supportive social networks, training opportunities that they can 'sell' elsewhere, and health education that may encourage HIV health practices and increase social status.

\section{Home-based care and 'linkages'}

According to The Lancet, trained CHWs are indispensable to achieving Millennium Development Goals, realization of which will require an estimated one million community health workers to be deployed in sub-Saharan Africa (SSA) by 2015 (Singh \& Sachs 2013:363). In particular, well-resourced and 
integrated community home-based care has been shown to transect many aspects of TasP initiatives outlined in global and national health plans (Wringe et al. 2010). Successful implementation of the WHO's interlocking elements for TasP will hinge largely on infrastructural capacities to reach expanded populations of HIV-positive and HIV-negative persons.

For SHBC, practical links with the public health sector have evolved in an ad hoc manner. One of the country's five government health centers (Nhlangano) is located at a distance of between 10 and 150 kilometers from SHBC clients. Coordinating, or "bridging," with public, private, donor, and other NGO entities has proven challenging for SHBC, as it has for community-based health groups in many parts of Africa (Wringe et al. 2010; Lees et al. 2012; Campbell \& Foulis 2004:10). Initially there was little in the way of communication between SHBC care supporters and clinic staff, possibly due to confusion and professional jealousies over SHBC's care work. Substantial rapport building and role clarification subsequently led to more constructive engagement, whereby clinic personnel began contacting the $\mathrm{COO}$ to inform her that a patient is being released and would benefit from home-based care. Formalization of such partnerships has been a key SHBC objective, yet it remains unclear how to proceed.

\section{Conclusion}

Researchers have pointed out repeatedly the need for extensive studies of the institutional, organizational, and environmental mechanisms to compensate for health sector shortages through home-based care, whether family, volunteer, or remunerated (Lees, Kielmann, Cataldo, \& Gitau-Mburu 2012; Ncama 2005). To better understand the operations and potential significance of $\mathrm{CHBC}$ in a high vulnerability setting, the importance of mitigating burnout among care supporters and directly addressing their wellbeing, and the disproportionate burden shouldered by women, this article provided a descriptive statistical analysis of an uncommonly large longitudinal dataset that generated insights on care supporter and client cohorts. The grassroots, volunteer, and faith-based components of SHBC outreach, the dire inadequacy of material 
and social support experienced by care supporters and clients alike, and lack of accessible health services are sufficiently characteristic of many such settings in Swaziland, and throughout Africa, that extrapolating insights to experiences of care supporters and PLWHA in similar regions was determined to be relevant and reasonable. It may be possible, therefore, to generalize from SHBC data to analysis of other CHBC configurations in areas with shared socio-cultural, economic, and epidemiological profiles, such as Lesotho and Botswana, to identify patterned challenges and responses.

SHBC's data collection and reporting practices in many ways distinguish it from many community-based initiatives. The organization has been able to track dramatic declines in client mortality, design data collection strategies to monitor and evaluate its services, and develop targeted initiatives to address clients' HIV health needs and to support its care supporters. Though it was not possible to establish causality between its services and declining mortality, by tracking key data on its care supporters and clients, as well as changing health practices and statuses, SHBC has been better able to plan and implement training sessions, including refresher trainings as new protocols and other relevant care practices come to light. Though volunteerism on the scale practiced by SHBC may be hard to replicate, its organizational features and training, and vigilance with respect to data collection, could help to strengthen organizations already providing home-based care elsewhere.

Critical to all aspects of task shifting is and will continue to be sustained training and support (material and comprehensive health) as well as monitoring and evaluation of organizational practices and potential health impact on both carers and clients. Toward this end, a better understanding of the HIVrelated impact of CHBC on care supporters' own health practices (e.g., are they more likely to test, to begin ART, to adhere, to disclose), would help $\mathrm{CHBC}$ to address important concerns over the negative impact of care work described in some CHBC and task-shifting literature. Finally, SHBC benefits to individual and community health would likely be best achieved through sustained strategic planning with public and private health providers. This coordination is a feat, however, that has thus far stymied similar stakeholders across 
the continent. In light of the centrality of $\mathrm{CHBC}$ to global and national health agendas, and well-documented concerns over burnout and the disproportionate care burden shouldered by women and girls, funding for both comparative and context-specific studies as well as urgent support measures for caregivers, are dual imperatives.

\section{Acknowledgements}

The authors are grateful to the care supporters at Shiselweni Home-based Care Organization, past and present, who both provided extraordinary care and counseling to their clients over the past decade and collected the majority of data on which this manuscript is based. The authors also thank reviewers of prior versions of this manuscript for their generous comments.

\section{References Cited}

Africa Health Workforce Observatory (2009) Human Resources for Health Country Profile Swaziland. World Health Organization. March. http://www.hrhobservatory.afro.who.int/images/Document Centre/Country profile Swaziland.pdf (accessed

Akintola. O. (2006) Gendered home-based care in South Africa: more trouble for the troubled. Gendered home-based care in South Africa: more trouble for the troubled. African Journal of AIDS Research 5(3), pp. 237-247.

Apondi R, Bunnell R, Awor A, Wamai N, Bikaako-Kajura W, Solberg P, et al. (2007) Homebased antiretroviral care is associated with positive social outcomes in a prospective cohort in Uganda. Journal of Acquired Immune Deficiency Syndrome 44(1), pp. 71-76.

AVERT (n.d.) HIV and AIDS in Swaziland. http://www.avert.org/hiv-aids-swaziland.htm (accessed Jan 21, 2014).

Bicego, G., Nkambule, R., Peterson, I., Reed, J., Donnell, D., Ginindza, H., et al. (2013) Recent patterns in population-based HIV prevalence in Swaziland. PLoS ONE 8(10), e77101.

Campbell, C. \& Foulis, C. (2004) Creating contexts for effective home-based care of people living with HIV/AIDS. Curationis 27 (3), pp. 5-14.

Campbell, C., Skovdal, M., \& Gibbs, A. (2011) Creating social spaces to tackle AIDS-related stigma: reviewing the role of church groups in sub-Saharan Africa. AIDS Behavior 15(6), pp. 1204-1219.

Campbell, C., Nair, Y., Sbongile, M., \& Zweni, S. (2008) Supporting people with AIDS and their carers in rural South Africa: possibilities and challenges. Health \& Place 14(3), pp. 507518.

Campbell, C., Nhamo, M., Scott, K., Madanhire, C., Nyamukapa, C., Skovdal, M, \& Gregson, S. (2013) The role of community conversations in facilitating local HIV competence: case study from rural Zimbabwe. BMC Public Health 13:354. doi:10.1186/1471-2458-13-354. 
CIA World Factbook. (2013) Swaziland Demographics Profile.

http://www.indexmundi.com/swaziland/demographics_profile.html (Feb 8, 2014).

Desmond, C., King, J., Tomlinson, J., Sithungo, C., Veenstra, N., \& Whiteside, A. (2004)

Using an undertaker's data to assess changing patterns of mortality and their consequences in Swaziland', African Journal of AIDS Research 3(1), pp. 45-50.

Escott, S. \& Walley, J. (2005) Listening to those on the frontline: Lessons for communitybased tuberculosis programmes from a qualitative study in Swaziland. Social Science \& Medicine 61(8), pp. 1701-1710.

Family Health International. (2004) Monitoring HIV/AIDS Programs. A Facilitator's training guide. A USAID resource for prevention, care and treatment. Module 4: Monitoring and Evaluating Community Home-based Care Programs.

http://www.fhi360.org/sites/default/files/media/documents/Monitoring\%20HIV-

AIDS\%20Programs\%20(Facilitator)\%20-\%20Module\%204.pdf (accessed February 9, 2014).

Forster, D. (2006) Identity in relationship: the ethics of Ubuntu as an answer to the impasse of individual consciousness. Paper presented at the South African Science and Religion Forum. In The Impact of Knowledge Systems on Human Development in Africa. Du Toit, C., ed. (2007). Pretoria, Research Institute for Religion and Theology, 245-289. Pretoria: UNISA.

Government of Swaziland. (2009) The National Multi-sectorial Strategic Framework for HIV/AIDS: 2009-2014. http://www.ilo.org/wcmsp5/groups/public/---ed_protect/---protrav/--ilo_aids/documents/legaldocument/wcms_174723.pdf (accessed Feb 10, 2014).

Hickel, J. (2012) Neoliberal Plague: The political economy of HIV transmission in Swaziland. Journal of Southern African Studies 38(3), pp. 513-529.

Joint United Nations Programme on HIV/AIDS (UNAIDS). (2013) Efficient and sustainable HIV responses: Case studies on country progress.

http://www.unaids.org/en/media/unaids/contentassets/documents/unaidspublication/2013/JC2 450_case-studies-country-progress_en.pdf (accessed Feb 10, 2014).

Kingdom of Swaziland. (2008) Service availability Mapping (SAM) 2006_2007. Kingdom of Swaziland: Ministry of Social Welfare and Ministry of Education. World Health Organization Regional Office for Africa.

http://www.infocenter.nercha.org.sz/sites/default/files/infocenter_db/ELDOCS/

SAM.pdf (accessed Sept 23, 2014).

Kingdom of Swaziland. (2012) Swaziland country report on monitoring the political declaration on HIV and AIDS. March.

http://www.unaids.org/en/dataanalysis/knowyourresponse/countryprogressreports/2012countri es/ce_SZ_Narrative_Report[1].pdf (accessed Feb 10, 2014).

Lees, S., Kielmann, K., Cataldo, F., \& Gitau-Mburu, D. (2012). Understanding the linkages between informal and formal care for people living with HIV in Sub-Saharan Africa. Global Public Health 7(10), 1109-1119.

Ministry of Health (Swaziland). (2013) Elimination of new HIV infections among children by 2016 and keeping their mothers alive. National Strategic Framework for Accelerated Action 2011-2015. UNICEF. http://www.zero-hiv.org/wpcontent/uploads/2013/03/Swaziland EMTCT-National-Strategic-Framework 20131.pdf (accessed Feb 3, 2014). 
Mwai, G., Mburu, G., Torpey, K., Frost, P., Ford, N., \& Seeley, J. (2013) Role and outcomes of community health workers in HIV care in sub-Saharan Africa: A systematic review. Journal of the International AIDS Society 16(1):18586.

Ncama, B. (2005) Models of community/home-based care for people living with HIV/AIDS in Southern Africa. Journal of the Association of Nurses AIDS Care 16, pp. 33-40.

Newman, C., Fogarty, L., Makoae, L., \& Reavely, E. (2011) Occupational segregation, gender essentialism and male primacy as major barriers to equity in HIV/AIDS caregiving: Findings from Lesotho. International Journal for Equity in Health 10:24.

Ogden, J., Esim, S., \& Grown, C. (2006) Expanding the care continuum for HIV/AIDS: bringing carers into focus. Health Policy \& Planning 21(5), pp. 333-342.

Opiyo, P. Yamano, T., \& Jayne, T. (2008) HIV/AIDS and home-based health care. International Journal for Equity in Health 7:8. PMCID: PMC2279120.

Reach Out Refugee Protection Training Project (2005) Optional module gender-based violence (GBV). http://www.unhcr.org/4371faad2.pdf (accessed May 19 2015).

Rödlach, A. (2009) Book Review. Heterosexual Africa? The History of an Idea from the Age of Exploration to the Age of AIDS, by Marc Epprecht. In Medical Anthropology Quarterly, 23(2), pp. 185-187.

Root, R. (2010) Situating experiences of HIV/AIDS in Swaziland. Global Public Health: An International Journal for Research, Policy and Practice 5(5), pp. 523-538.

Root, R. \& Van Wyngaard, A. (2009) Free love: A case study of church run home-based caregivers in a high vulnerability setting. Global Public Health: An International Journal for Research, Policy and Practice 6:sup2, pp. S174-S191.

Root, R. \& Whiteside, A. (2013) A qualitative study of community home-based care and antiretroviral adherence in Swaziland. Journal of the International AIDS Society 16:17978. http://dx.doi.org/10.7448/IAS.16.1.17978.

Selke, H., Kimaiyo, S., Sidle, J., Vedanthan, R., Tierney, W., Shen, C., Denski, C., Katschke, A., Wools-Kaloustian, K. (2010) Task-shifting of antiretroviral delivery from health care workers to persons living with HIV/AIDS: clinical outcomes of a community-based program in Kenya. Journal Acquired Immune Deficiency Syndrome 55(4), pp. 483-90.

Sibbald, B. (2013) HIV prevention; new pilot for beleaguered Swaziland. The Lancet 381(9861), pp. 103-104.

Singh, P., and Sachs, J. (2013) One million community health workers in sub-Saharan Africa by 2015. The Lancet 382(9889), pp. $363-365$.

Smith, AD and GlobalPost (2012) Which a US Circumcision Push Failed in Swaziland. PBS Newshour. (July 5) http://www.pbs.org/newshour/updates/health-july-dec12-swaziaids 07-05/ (accessed Jan 21, 2014).

Stop AIDS Now! MaxART - Implementation Study on Treatment as Prevention. Nd. http://www.stopaidsnow.org/node/322 (accessed Feb 2, 2014).

Swaziland National Network of People Living with HIV/AIDS [SWANNEPHA]. (2011) Assessment of the Stigma Index among People Living with HIV/AIDS in Swaziland.

www.stigmaindex.org/download.php?id=94 (accessed Feb 11, 2014). 
United Nations. (2012) Swaziland 2012.

http://sz.one.un.org/index.php?option=com_content\&view=article\&id=36:responding-to-hiv-aaids-in-swaziland\&catid=28:hiv-a-aids\&Itemid=34 (accessed Feb 4, 2014).

University Research Co., LLC. (2010) Increasing HIV Testing and Counselling in the Kingdom of Swaziland. Centers for Disease Control. http://www.urcchs.com/uploads/resourcefiles/Swazilandtechnicalbrief.pdf (accessed Feb 14, 2014).

Uys, L. (2003a) Aspects of the care of people with HIV/AIDS in South Africa. Public Health Nursing 20(4), pp. 271-280.

Uys, L. (2003b) Guest Editorial: Longer-term aid to combat AIDS. Journal of Advanced Nursing 44(1), pp. 1-2.

Van Wyngaard, A. (2006a) 'On becoming the hands and feet of Christ in an AIDS-ridden community in Swaziland - A story of hope', Verbum et Ecclesia 27(3), pp. 1095-1109.

Van Wyngaard, A. (2006b) Towards a theology of AIDS. REC Focus 6(1-2), pp. 51-75.

Van Wyngaard, A. (2013) Addressing the Spiritual Needs of People Infected With and Affected by HIV and AIDS in Swaziland. Journal of Social Work in End-Of-Life \& Palliative Care, 9(2-3), pp. 226-240.

Whiteside, A., Andrade, C., Arrehag, L., Dlamini, S., Ginindza, T., \& Parikh, A. (2006) The socio-economic impact of HIV/AIDS in Swaziland. National Emergency Response Council on HIV/AIDS and Health Economics \& HIV/AIDS Research Division. http://gametlibrary.worldbank.org/FILES/1619_Socioeconomic\%20Impact\%20of\%20AIDS\%20-\%20Swaziland.pdf (accessed May 19, 2015).

Whiteside, A., Desmond, C., King, J., Tomlinson, J., \& Sithungo, C. (2002) Evidence of AIDS mortality from an alternative source: A Swaziland case study. African Journal of AIDS Research 1(1-4), pp. 37- 40.

World Health Organization. (2008) Task shifting: rational redistribution of tasks among health workforce teams: global recommendations and guidelines.

http://www.who.int/healthsystems/TTR-TaskShifting.pdf?ua=1 (accessed Feb 9, 2014).

World Health Organization. (2009) Swaziland Country Cooperation Strategy.

World Health Organization. (2010) Swaziland Analytical Summary.

http://www.aho.afro.who.int/profiles_information/index.php/Swaziland:Analytical_summary__Health_Status_and_Trends (accessed Feb 8, 2014).

World Health Organization. (2013a, June 30) WHO issues new HIV recommendations calling for earlier treatment.

http://www.who.int/mediacentre/news/releases/2013/new_hiv_recommendations_20130630/e n/index.html (accessed Feb 9, 2014).

World Health Organization. (2013b, June 30) WHO Consolidated ARV Guidelines, June 2013. Chapter 6: Clinical guidelines across the continuum of care: linking people diagnosed with HIV infection to HIV care and treatment.

http://www.who.int/hiv/pub/guidelines/arv2013/treatment/en/index.html (accessed Jan 23, 2014) and Chapter 1 http://www.who.int/hiv/pub/guidelines/arv2013/treatment/en/index.html (accessed Feb 9, 2014). 
World Health Organization. (2013c) Swaziland Country Cooperation Strategy.

http://www.who.int/countryfocus/cooperation_strategy/ccsbrief_swz_en.pdf (accessed Feb 8, 2014).

World Health Organization. (2014, May) Swaziland: health profile.

http://www.who.int/gho/countries/swz.pdf?ua=1 (accessed Jan 17, 2014).

Wringe, A., Cataldo, F., Stevenson, N., \& Fakoya, A. (2010) Delivering comprehensive homebased care programmes for HIV: a review of lessons learned and challenges ahead in the era of antiretroviral therapy. Health Policy and Planning 25(5), pp. 352-662.

Zachariah, R., Ford, N., Philips, M., Lynch, S., Massaquoi, M., \& Janssens, V. (2009) Task shifting in HIVIAIDS: opportunities, challenges and proposed actions for sub-Saharan Africa. Transactions of the Royal Society of Tropical Medicine and Hygiene 103 (6): 549-558

Zwane, I. (2005) Assessing quality of care and responsiveness of health services for women in crises settings. Swaziland Case Study. Consultant for WHO.

http://www.who.int/hac/techguidance/pht/womenshealth/Swaziland_report_women_in_crisis_j une2005.pdf (accessed Feb 5, 2014). 